\title{
REDESCRIPTION OF HYPOASPISELLA PINI (HIRSCHMANN, BERNHARD, GREIM AND GÖTZ) COMB.N. (ACARI: MESOSTIGMATA: LAELAPIDAE) WITH A KEY TO WORLD SPECIES OF HYPOASPISELLA WITH SETAE ST1 OFF STERNAL SHIELD
}

\author{
Omid Joharchi ${ }^{*}$, Cihan Cilbircioğlư ${ }^{2}$, İsmail Döker ${ }^{1,3}$ and Vladimir A. Khaustov ${ }^{1}$ \\ ${ }^{1} \mathrm{X}-\mathrm{BIO}$ Institute, Tyumen State University, Tyumen, Russia \\ ${ }^{2}$ Vocational School Organic Agriculture Department, University of Kastamonu Taşköprü, \\ Kastamonu, Turkey \\ ${ }^{3}$ Acarology Laboratory, Department of Plant Protection, Agricultural Faculty, Cukurova \\ University, Adana, Turkey \\ *corresponding author; e-mail: j.omid2000@gmail.com
}

\begin{abstract}
Hypoaspisella pini comb. $n$. is redescribed based on adult females collected from a rotten stump of Siberian spruce (Picea obovata Ledeb.) in Western Siberia (Russia) and from the galleries of Ips acuminatus (Gyllenhal) (Coleoptera: Curculionidae: Scolytinae) in Turkey. Hypoaspisella pini fits well with the current concept of the genus Hypoaspisella Bernhard. The chelicerae of this species are similar to those of free-living forms, which suggests it may be a predator of small invertebrates, inhabiting bark beetle galleries and decomposing organic matter. Moreover, we provide a world key to the species of Hypoaspisella with setae st1 off sternal shield.
\end{abstract}

KEY WORDS: Mite, Parasitiformes, Gamasina, Dermanyssoidea, Hypoaspidinae, taxonomy.

DOI: 10.21684/0132-8077-2020-28-2-193-202

\section{INTRODUCTION}

Laelapidae is a cosmopolitan mite family characterized by an unusually diverse variety of lifestyles and habitats. Hypoaspisella Bernhard is a group of predatory laelapids commonly encountered in soils (like Gaeolaelaps species). The representatives of this group probably prey on nematodes, acarid mites and other soft-bodied arthropods abound in soil and decomposing organic matter. In his Ph.D. thesis (not seen by us), Bernhard (1955) described the genus Hypoaspisella as a subgenus of Hypoaspis Canestrini sensu lato. However, this action does not satisfy the Article 8.1.3 of the International Code of Zoological Nomenclature (ICZN 1999) for considering Hypoaspisella a valid subgenus. Bernhard (1971) then provided a more complete description of "Hypoaspisella nov. subgen." and stated that its type species is "Hypoaspisella berlesei nov. spec.". However, this work by Bernhard overlooked the fact that Karg (1962) had designated H. heyi as the type species, and that $H$. berlese $i$ had been made available by Hirschmann et al. (1969) for Hypoaspisella. Soon afterwards, Karg (1979) considered Hypoaspisella as a synonym of Pneumolaelaps by placing Hypoaspis (Hypoaspisella) heyi in Hypoaspis (Pneumolaelaps). This has probably led to the misinterpretation and ambiguity in the genus Hypoaspisella's definition. For this reason, many authors (e.g., Faraji et al. 2008; Kazemi and Rajaei 2013; Moreira 2014; Kavianpour et al. 2017; Nemati et al. 2018) could not decide on the correct generic placement of many real Hypoaspisella species, choosing to place them into Hypoaspis (Pneumolaelaps), Pneumolaelaps, or a very broadly conceived genus $\mathrm{Hy}$ poaspis sens. lat.

Finally, Joharchi et al. (2018) raised Hypoaspisella Bernhard to genus and revised its morphological attributes. The genus Hypoaspisella is superficially similar in its morphology to Gaeolaelaps Evans and Till and Pneumolaelaps Berlese. This problem was briefly discussed by Joharchi et al. (2018), who attempted to distinguish the above genera. During a survey of free-living and insect-associated species of laelapid mites in Western Siberia (Russia) and Turkey, a series of female specimens identified as Hypoaspisella pini (Hirschmann, Bernhard, Greim and Götz) were collected from a rotten stump of Siberian spruce (Picea obovata) and from the galleries of Ips acuminatus (Gyllenhal) (Coleoptera: Curculionidae: Scolytinae), respectively. Hypoaspisella pini was originally described from a spruce stump in Germany and considered a member of a very broadly conceived genus Hypoaspis sensu lato by Hirschmann, Bernhard, Greim and Götz (1969). However, the original description is brief and its illustrations are incomplete, lacking most important details, especially those concerning leg chaetotaxy. Thus, the species has never been fully redescribed.

Towards this aim, we herein redescribe the female of Hypoaspisella pini based on the speci- 
mens collected from Russia and Turkey. We also provide a revised diagnosis of some of the species. Moreover, we provide a world key to the species of Hypoaspisella with setae st 1 off sternal shield.

\section{MATERIALS AND METHODS}

Mites were extracted from the bark beetle galleries and from the rotten spruce stump using Berlese-Tullgren funnels. Mites were cleared in lactic acid solution and mounted in Hoyer's medium (Walter and Krantz 2009). The line drawings and examinations of the specimens were performed with the Zeiss Axio Imager A2 and Leica DM 2500 compound microscopes, equipped with the differential interference contrast and phase contrast optical systems, attached to the AxioCam ICc 5 and ICC50 HD cameras, respectively. Figures were elaborated with Adobe Photoshop CS2 software based on the line drawings. Images and morphological measurements were taken via ZEN 2012 software (v. 8.0) and Leica Application Suite (LAS) software (v. 4.2, Live and Interactive Measurements modules). Micrographs were taken with the AxioCam 506 camera (Carl Zeiss, Germany).

Measurements of structures are expressed as ranges (minimum-maximum) in micrometres $(\mu \mathrm{m})$. The length and the width of the dorsal shield were taken from the anterior to the posterior margins along the midline and at the level of $r 3$, respectively. The length of the sternal shield was measured at the maximum length. The width of the sternal shield was measured at the broadest points (at the level of the endopodal between coxae II and III). The length of the genital shield was measured along the midline from the anterior margin of the hyaline extension to the posterior margin of the shield. The width of the genital shield is maximal, measured posteriorly to genital setae $s t 5$. Leg length was measured from the base of the coxa to the apex of the tarsus (excluding pre-tarsus).

The nomenclature used for the dorsal idiosomal chaetotaxy follows that of Lindquist and Evans (1965). The notations for leg and palp setae follow those of Evans (1963a, 1963b). Other anatomical structures mostly follow Evans and Till (1979). Notations for the idiosomal pore-like structures (gland pores and poroids/lyrifissures) and for the peritrematal shield follow mostly Athias-Henriot $(1971,1975)$. The notations for pore-like structures located on the sternal shield and on the peritrematal shield region also follow modifications and additions by Johnston and Moraza (1991), adapted by Kazemi et al. (2014).
All examined specimens are deposited in the acarological collection of the Tyumen State University Museum of Zoology, Tyumen, Russia (TUMZ).

\section{SYSTEMATICS}

\section{Family Laelapidae Genus Hypoaspisella Bernhard}

Hypoaspis (Hypoaspisella) Bernhard, in Karg 1962: 64. Type species Hypoaspis (Hypoaspisella) heyi Karg, 1962, by monotypy. Hypoaspis (Hypoaspisella) Bernhard, 1971: 6. Type species Hypoaspisella berlesei Bernhard, in Hirschmann et al. (1969), by original designation.

Diagnosis. The concept of Hypoaspisella used here is based on that of Joharchi et al. (2018), which also includes a discussion of the nomenclatural history of the name.

\section{Hypoaspisella pini (Hirschmann, Bernhard, Greim and Götz), comb.n}

\author{
(Figs. 1-3)
}

Hypoaspis pini Hirschmann, Bernhard, Greim and Götz, 1969: 140.

Hypoaspis ninabregus McGraw and Farrier, 1969: 144 [synonymy by Karg 1982: 246; Karg 1993: 152].

Hypoaspis ninabregus.-Farrier and Hennessey 1993: 78.

Hypoaspis (Pneumolaelaps) pini.-Karg 1979:

92; Karg 1982: 246; Karg 1993: 152.

Pneumolaelaps pini.-Moreira 2014: 358.

Diagnosis (female). Dorsal shield with weak reticulation, more distinct in opisthonotal and lateral regions, bearing 40 pairs of setae, 22 pairs of podonotal setae and 18 pairs of opisthonotal setae, including three pairs of $Z x$ setae, two supernumerary setae $J x$ present between $J$-series. All setae relatively long, almost reaching base of next posterior setae, lengths of setae slightly increasing from anterior to posterior and from central to lateral. Presternal area lightly sclerotized, with a few transverse curved lines, sternal shield with reticulate ornamentation throughout, except posterior part smooth (or faintly reticulated), bearing two pairs of smooth pointed setae, st 1 off shield, anterior and posterior margins slightly convex and concave, respectively, endopodal plates III/IV elongate, narrow and curved, ratio of shield length/ width (at broadest level) $\simeq 0.74$. Genital shield elongated, ratio of length/ width (at broadest level) $\simeq 2.2$, 


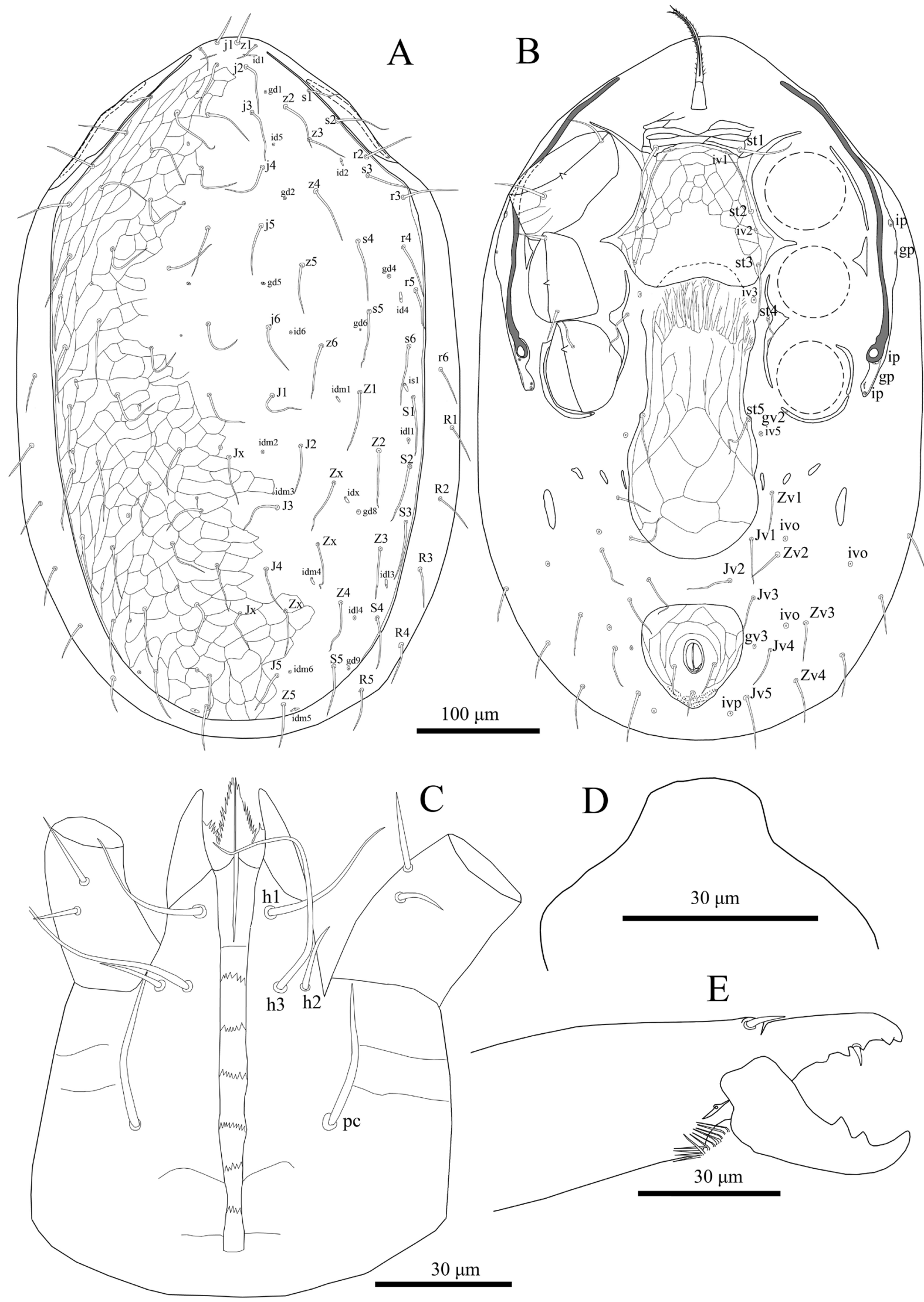

Fig. 1. Hypoaspisella pini (Hirschmann, Bernhard, Greim and Götz, 1969), female. A—dorsal idiosoma; B—ventral idiosoma; C-subcapitulum; D - epistome; E-chelicera. 


\section{O. Joharchi et al.}
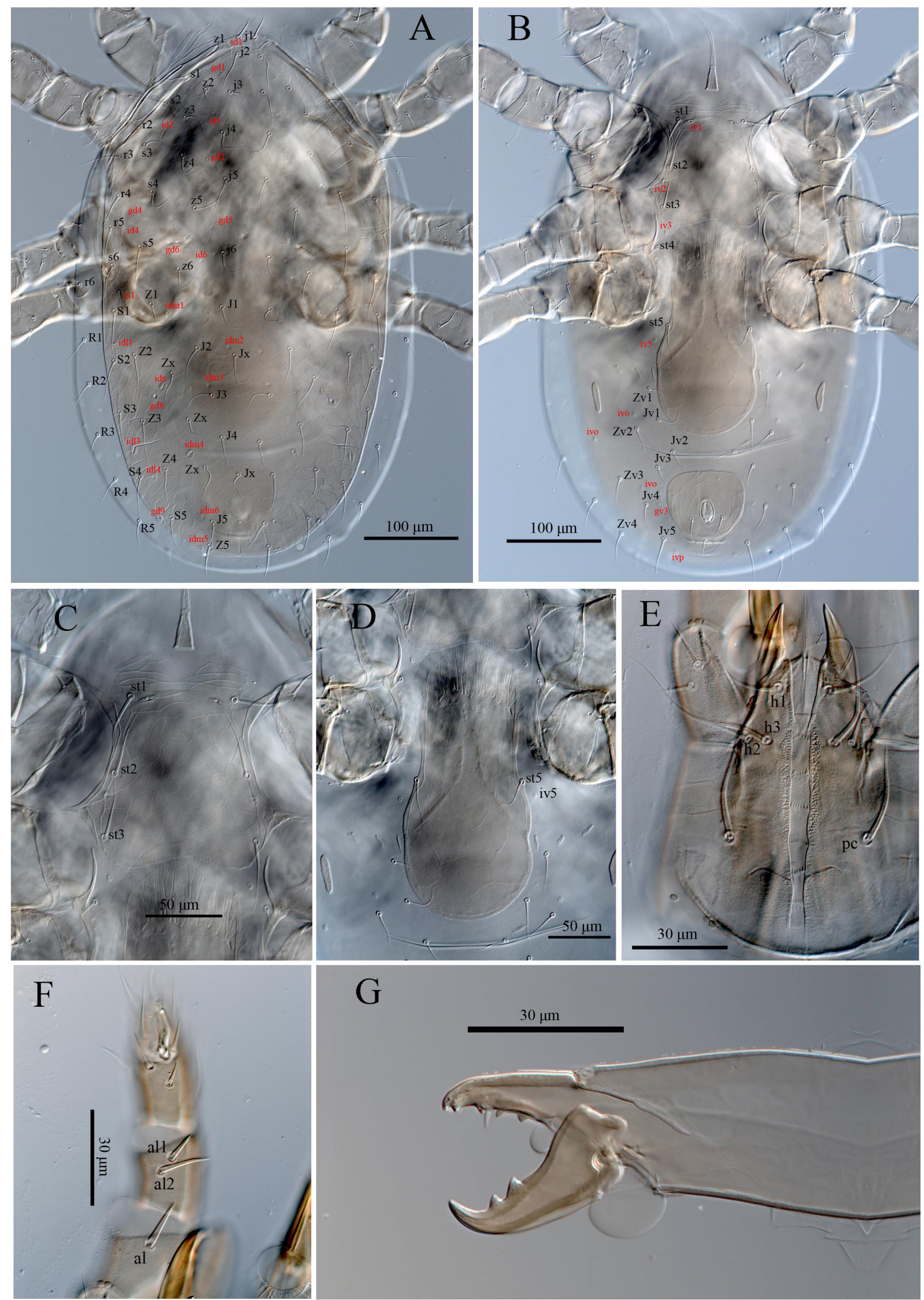

\section{G}
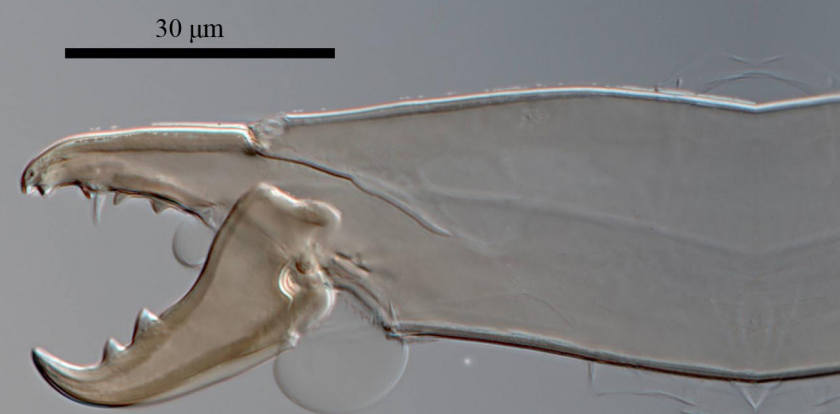

Fig. 2. DIC micrographs of Hypoaspisella pini (Hirschmann, Bernhard, Greim and Götz, 1969), female. A—idiosoma in dorsal view; B - idiosoma in ventral view; $\mathrm{C}$ - sternal shield; D-genital shield and opisthogastric area; Esubcapitulum; F-distal portion of palp, with a focus on apotele; G-chelicera. 

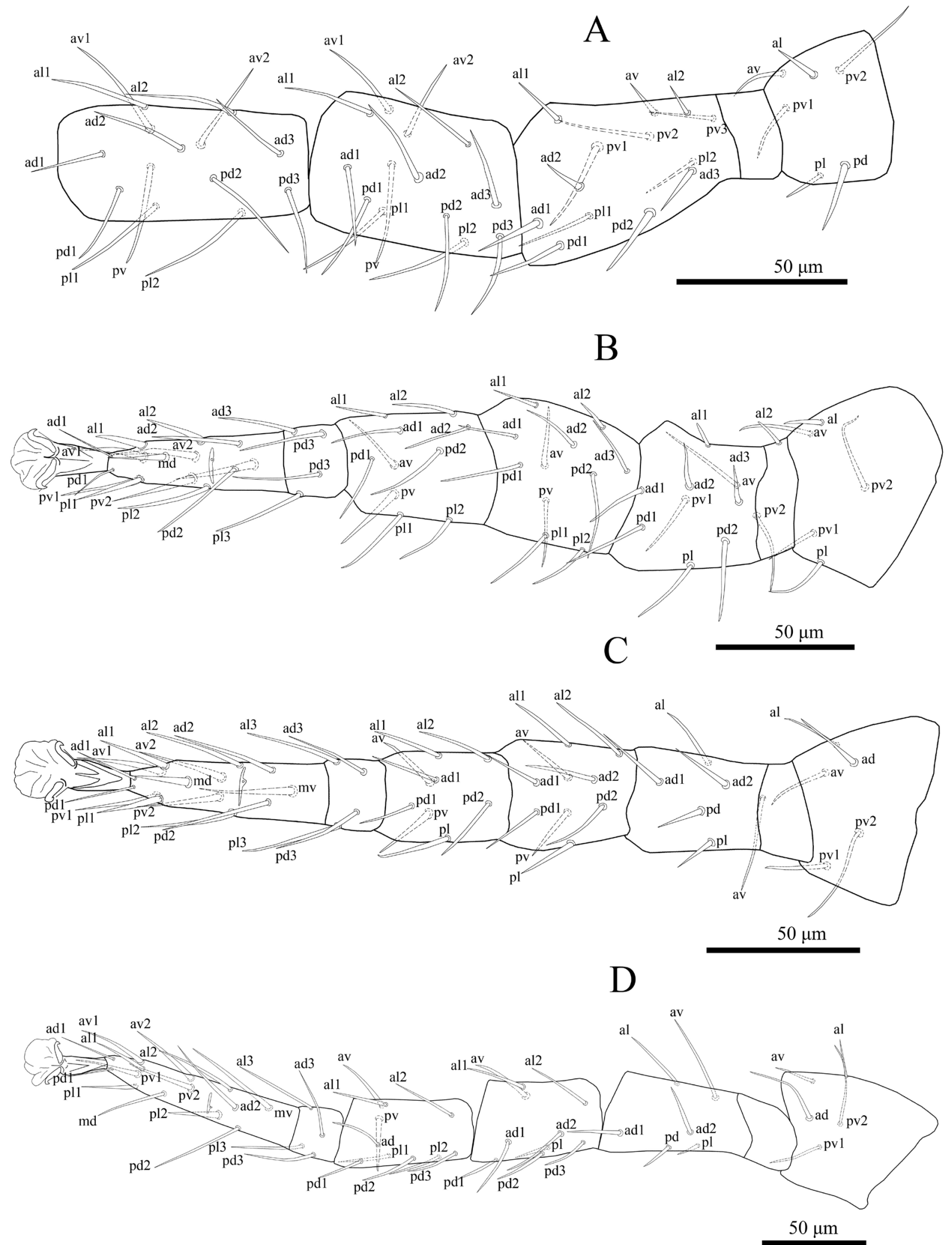

Fig. 3. Hypoaspisella pini (Hirschmann, Bernhard, Greim and Götz, 1969), female. A—leg I (trochanter-tibia); B-leg II; C-leg III; D-leg IV.

surface reticulated with irregular, mostly longitudinal lines in anterior region, posteriorly comprising 7-8 polygonal cells enclosed behind an in- verted V-shaped ridge. Anal shield with length/ width ratio (at broadest level) $\simeq 1.07$, para-anal setae longer than post-anal seta. Opisthosomal 
integument with 12 pairs of smooth setae and three pairs of oval metapodal plates, peritremes long, reaching to slightly beyond mid-level of coxae I. Ventral and lateral setae on tarsi II-IV spine-like. Palp tarsal apotele two-tined, fixed digit of chelicera with four teeth and epistome smooth.

Redescription. Female $(\mathrm{n}=14)$.

Dorsal idiosoma (Figs. 1A, 2A). Dorsal idiosoma 540-586 long, 331-361 wide, dorsal shield oval-shaped, 490-569 long, 280-365 wide, covering most of dorsal idiosoma, narrow strip of unsclerotized integument surrounding the shield, shield with weak reticulation, more distinct in opisthonotal and lateral regions. Shield bearing 40 pairs of setae (40-50), 22 pairs of podonotal setae and 18 pairs of opisthonotal setae, including three pairs of $Z x$ setae, two supernumerary setae $J x$ present between $J$-series, $j 1$ (22-27), zl (20-23), Z5 (35-37) (Figs. 1A, 2A). All setae relatively long, almost reaching base of next posterior setae, lengths of setae slightly increasing from anterior to posterior and from central to lateral. Shield with 23 pairs of discernible pore-like structures, including 16 poroids (idl, id2, id4-6, idm1-idm6, idx, is 1, idl1, $i d l 3-4)$ and seven gland openings ( $g d 1-2, g d 4-6$, gd8-9) (Figs. 1A and 2A). Dorsolateral soft integument bearing six pairs of setae, $r 6, R 1-5$ (28-35).

Ventral idiosoma (Figs. 1B, 2B-D). Tritosternum with paired pilose laciniae (62-66), fused basally (4-7), columnar base 23-28 × 12-14 wide; presternal area lightly sclerotized and with a few transverse curved lines. Sternal shield (length 114-121) narrowest between coxae II (89-92), widest (155-162), anterior and posterior margins slightly convex and concave, respectively; bearing two pairs of smooth setae (46-50) (st2, st3), st 1 (46-50) off shield, on poorly sclerotized cuticle (Fig. 2C), one pair of lyrifissures adjacent to setae $s t 1$, and a pair of oval shape poroids between $s t 2$ and $s t 3$; setae almost reaching base of next setae; sternal shield with reticulate ornamentation throughout, except posterior part smooth (or faintly reticulated) (Fig. 2C). Metasternal setae st4 (35-37) and metasternal poroids located on soft integument; metasternal platelets absent. Endopodal plates II/ III completely fused to sternal shield, endopodal plates III/IV elongate, narrow and curved, their anterior ends obviously free from posterolateral angles of sternal shield. Genital shield elongated, slightly expanded laterally past level of setae st 5 (Fig. 2D), length 224-244, maximum width 101110 , anterior margin of shield irregularly convex, overlapping posterior area of sternal shield, but not reaching base of setae $s t 3$, posterior margin rounded, clearly separated from anal shield, the distance midline between posterior margin of genital shield and anterior margin of anal shield nearly one-half as long as anal shield, surface reticulated with irregular, mostly longitudinal lines in anterior region, posteriorly comprising 7-8 polygonal cells behind an inverted $\mathrm{V}$-shaped ridge; bearing a pair of simple setae $s t 5$ (41-43); shield flanked by a pair of minute, elongate paragenital platelets, paragenital poroids iv5 located on soft cuticle lateral to shield near seta $s t 5$. Anal shield subtriangular, rounded anteriorly, length 81-90, width 78-84, anterior half lineatereticulate, para-anal setae (24-27) longer than postanal seta (20-22), cribrum small, with 3-4 irregular rows of spicules, mostly limited to region posterior to post-anal seta, except a pair of anterior rows reaching to about mid-level of distance between post-anal and para-anal setae; anal gland pores $g v 3$ located on soft opisthogastric cuticle close to shield. Soft opisthogastric cuticle with three pairs of oval metapodal plates, most lateral largest (27-34 long $\times$ 7-9 wide) and 12 pairs of smooth setae ( $J v 1-J v 5$, $Z v 1-Z v 4, U R 2-U R 4)(30-42)$ and five pairs of poroids, including $i v 5$ and ivp. Exopodal platelets between coxae II-III divided into sclerotised strips along coxae II-III and subtriangular part, those behind coxae III-IV and parapodal platelets contiguous, strip-like, extending narrowly behind coxae IV, bearing gland pore gv2 (Fig. 1B). Peritreme extending anteriorly to slightly beyond midlevel of coxa I; peritrematal shield narrow, more or less expanded anteriorly, fused to dorsal shield behind setae $z 1$, bearing five pore-like structures, a lyrifissure ip and a gland pore $g p$ at level of between coxae II-III, two lyrifissures $i p$ and a gland pore $g p$ on post-stigmatic section (Fig. 1B).

Gnathosoma (Figs. 1C-E and 2E-G). Epistome subtriangular, with entirely smooth margin (Fig. 1D). Hypostomal groove with six rows of denticles, each row with 4-9 denticles, with smooth anterior and posterior transverse lines (Figs. 1C and 2E). Hypostome with four pairs of setae, internal posterior hypostomal setae $h 3$ (60-63), $h 1$ (23-26), $h 2$ (14-19), palpcoxal $p c$ (36-39) (Figs. 1C and 2E). Internal malae fringed, with a pair of adjacent median pilose projections, flanked by a pair of shorter and thinner lateral projections (Figs. 1C and 2E). Corniculi robust and horn-like, extending slightly beyond palptrochanter. Supralabral process indistinct. Chaetotaxy of palps: trochanter 2, femur 5 , genu 6 , tibia 14 , tarsus 15 , all setae smooth and needle-like except all on palpfemur and all, al2 
on palpgenu thickened, palp tarsal apotele twotined (Fig. 2F). Fixed digit of chelicera with an offset and most distal tooth (gabelzhan), followed by three almost-same-sized teeth, a setaceous pilus dentilis, dorsal cheliceral seta prostrate, arthrodial membrane with a rounded flap and normal filaments; cheliceral lyrifissures distinct, movable digit with two teeth (Figs. 1E, 2G).

Legs (Fig. 3A-D). Legs II (339-345) and III (330-333) short, I (398-405) and IV (447-451) longer. Chaetotaxy normal for free-living Laelapidae: Leg I (Fig. 3A): coxa 0-0/1, 0/1-0, trochanter $1-0 / 1,1 / 2-1$ ( $p d$ and al slightly thickened), femur 2-3/1, 2/3-2 ( $a d 1, p d 3$ and $p v 1$ slightly thickened), genu 2-3/2, 3/1-2, tibia 2-3/2, 3/1-2. Leg II (Fig. $3 \mathrm{~B})$ : coxa $0-0 / 1,0 / 1-0$, trochanter $1-0 / 1,0 / 2-1$ (al slightly thickened), femur 2-3/1, 2/2-1 (ad2, ad3 thickened, $p d 2$ longest), genu 2-3/1, 2/1-2 ( $p d 2$ longest), tibia 2-2/1, 2/1-2 ( $p v$ thickened, $p d 2$ longest). Leg III (Fig. 3C): coxa 0-0/1, 0/1-0, trochanter 1-1/1, 0/2-0 ( $p v 2$ longest), femur 1-2/1, 1/0-1, genu 2-2/1, 2/1-1 (all ventral setae thickened), tibia: 2-1/1, 2/1-1 (all ventral setae thickened). Leg IV (Fig. 3D): coxa 0-0/1, 0/0-0, trochanter 1-1/1, 0/2-0 ( $p v 2$ longest), femur 1-2/1, 1/0-1 ( $a v$ longest), genu 2-2/1, 3/0-1 ( $a v$ thickened), tibia 2-1/1, 3/1-2 ( $a v$ and $p v$ thickened). Tarsi II-IV with 18 setae (3-3/2, 3/2-3 + mv, $m d)$; tarsus II-IV with some spine-like ventral and lateral setae, (Fig. 3B-D). All pretarsi with well-developed paired claws, rounded pulvilli and normal ambulacral stalk.

Specimens examined and deposition: four females, Russia, Tyumen Region, vicinity of the Uspenka village, $57^{\circ} 04^{\prime} \mathrm{N}, 65^{\circ} 04^{\prime} \mathrm{E}, 27$ June 2020 , coll. O. Joharchi, from a rotten Siberian spruce stump (Picea obovata Ledeb.); ten females, Turkey, Black Sea Region, Kastamonu Province, Taşköprü District, Karadedeoğlu Forests, $41^{\circ} 22^{\prime} \mathrm{N}, 34^{\circ} 25^{\prime} \mathrm{E}$, alt. 1,248 m, 2 August 2018, coll. C. Cilbircioğlu, in the galleries of Ips acuminatus (Gyllenhal) (Coleoptera: Curculionidae: Scolytinae) on Pinus nigra L. (Pinaceae).

Remarks. We were unable to locate the types of Hypoaspisella pini, but the following ecological, geographic and morphological features suggest that the specimens which we examined are conspecific with those described by Hirschmann et al. (1969) as Hypoaspis pini: (1) host-specific (on spruce stump); (2) distributed in Europe and Asia; (3) morphological features (e.g., the shape and the reticulation patterns of the genital and sternal shields, the length of the dorsal setae, denticulation of chelicera in female, body size).
Hypoaspisella pini was described from Germany (Hirschmann, Bernhard, Greim and Götz 1969) where it was recorded from a spruce stump. Although our efforts to view the type material were unsuccessful, our specimens are in perfect agreement with the description of $H$. pini given by Hirschmann, Bernhard, Greim and Götz (1969). Karg (1982) assigned H. pini to Hypoaspis (Pneumolaelaps), dentipilosa species group (dorsal shield with 1-3 unpaired $J x$ setae). He also considered it a junior synonym of Hypoaspis ninabregus McGraw and Farrier, 1969. However, Karg (1982) did not provide any explanation for this decision, nor did he provide the details of the examined specimens. Hypoaspis ninabregus was described from North Carolina, USA (McGraw and Farrier, 1969), where it was found in the galleries of different bark beetle species (e.g., Dendroctonus frontalis Zimmermann, Ips avulsus (Eichhoff), Ips grandicollis (Eichhoff) (Coleoptera: Curculionidae: Scolytinae)), on shortleaf pine (Pinus echinata Miller). We have not had the opportunity to examine the type specimens of $H$. ninabregus. Nonetheless, in the process of comparing the descriptions and figures of these species with our observations of the West Siberian and Turkish specimens, we could not find any distinguishing authentic morphological differences, except: 1) dorsal shield weakly reticulated in $H$. pini (more distinct in opisthonotal and lateral regions), while in $H$. ninabregus smooth throughout; and 2) genital shield posteriorly comprising 7-8 polygonal cells behind an inverted $\mathrm{V}$-shaped ridge in $H$. pini, while it is smooth in H. ninabregus. We believe that such morphological differences may represent intraspecific variation among two different geographical zones. Therefore, in this study, we follow Karg's (1982) treatment and provisionally retain these two species as synonyms until further comparative studies clarify their relationship.

We consider $H$. pini to be a member of $H y$ poaspisella because this species agrees well with Hypoaspisella in the following main character states: dorsal shield sub-oval and bearing 40 pairs of simple setae (including $Z x$ setae); dorsolateral soft integument with six pairs of simple setae; presternal region weakly sclerotized; shapes of sternal and genital shields normal for genus; setae $s t 4$ on soft cuticle; genital shield bearing a pair of setae; anal shield sub-triangular; epistome subtriangular and anterior margin entirely smooth; internal malae fringed, with a pair of adjacent median pilose projections, flanked by just a pair of shorter and thinner lateral projections; deutosternal groove 
with six rows of denticles, each row bearing 4-9 denticles; peritremes long extending to coxa I; peritrematal shield not enlarged around stigmatic opening; opisthogastric soft cuticle bearing 12 pairs of smooth pointed setae; all legs with ambulacra and claws; leg chaetotaxy normal for Laelapidae and genu IV with nine setae (2-2/1, 3/0-1).

H. pini has an unusual character state: setae $s t 1$ off sternal shield. The sternal shield in Hypoaspisella usually bears three pairs of setae; setae st 1 is rarely off shield in the presternal region. However, seta $s t l$ being off the sternal shield in the presternal region can be difficult to discern. We have not had the opportunity to examine any type specimens of Hypoaspis hermonensis Costa, 1969 and Hypoaspis antipai (Solomon, 1968). Nonetheless, by comparing the descriptions and figures of these two species we found that $H$. hermonensis and $H$. antipai share many compelling characters, such as: the length of the dorsal shield setae (the length of setae longer than half the distance of the following setae in series but never reaching the base of the next posterior setae); the shape of the epistome (subtriangular, with entirely smooth margin); the shape and the reticulation of the sternal and genital shields (reticulated throughout); the shape of the posterior part of the peritrematal shields (peritrematal shields posteriorly fused with exopodal shields IV); both species have been recorded from the nests of small mammals. Thus, it is conceivable that Costa (1969) has described the same species under the new name $H$. hermonensis. Therefore, Hypoaspis hermonensis could be junior synonyms of Hypoaspis antipai. However, further studies carefully comparing these two species are needed.

On the other hand, Karg (1979) suspected that H. antipai and Hypoaspis grandiporus (Greim in Hirschmann et al., 1969) are synonyms. We have not had the opportunity to examine the type specimens of $H$. grandiporus in order to confirm the suspicion of synonymy, but, again, by comparing the descriptions and figures of these two species, we found a distinguishing morphological difference: sternal setae $s t 1$ is off the sternal shield in $H$. antipai, while in H. grandiporus it is obviously on the shield. Therefore, we believe these are two distinct species.

Lapina (1976) described Hypoaspis heyi var. latvicus, accompanied by some illustrations, from Latvia. The first author of the present article had the chance to examine the holotype of Hypoaspis heyi in Karg's collection (ZMB Kat. Nr. 40304), deposited in the Museum für Naturkunde Berlin,
Germany. We could not find any distinguishing authentic morphological differences between the holotype and Lapina's (1976) H. heyi var. latvicus.

The following key is based on published descriptions and illustrations, except for $H$. pini, $H$. spiculifer and $H$. heyi.

\section{Key to species of Hypoaspisella with setae st 1 off sternal shield}

1. Opisthonotal region of dorsal shield without unpaired supernumerary setae $J x$ between $J$-series.... 2 - Opisthonotal region of dorsal shield with unpaired supernumerary setae $J x$ between $J$-series............... 4

2. Leg I as long as leg IV or a bit shorter............ 3 — Leg I obviously longer than leg IV

... Hypoaspisella antipai (Solomon, 1968) comb.n. $[?=$ Hypoaspis hermonensis (Costa, 1969)]

3. Dorsal setae relatively long, length of most podonotal setae more than half the distance of the following setae in series, fixed digit of chelicera with eight teeth............ Hypoaspisella heyi (Karg, 1962) - Dorsal setae relatively short, length of most podonotal setae less than half the distance of the following setae in series, fixed digit of chelicera with six teeth............... Hypoaspisella azarbaijaniensis (Faraji, Abedi and Ostovan, 2008) comb.n. 4. Opisthonotal region of dorsal shield bearing 18 pairs of setae, including three pairs of $Z x$ setae .... 5 - Opisthonotal region of dorsal shield bearing 17 pairs of setae, including two pairs of $Z x$ setae ....6 5. Genital shield longer than wide, ratio of length/ width (at broadest level) $\simeq 2.2$, fixed digit of chelicera with four prominent teeth....Hypoaspisella pini — Genital shield wider than long, ratio of length/ width (at broadest level) $\simeq 0.9$, fixed digit of chelicera with three small teeth .......................... Hypoaspisella giffordi (Evans and Till, 1966) comb.n. 6. Genital shield elongated, extending close to anal shield, the distance midline between posterior margin of genital shield and anterior margin of anal shield nearly as long as anal opening, soft opisthogastric cuticle with three pair of oval metapodal plates .... Hypoaspisella spiculifer (Berlese, 1918) - Genital shield not elongated, the distance midline between posterior margin of genital shield and anterior margin of anal shield nearly more than twice as long as anal shield, soft opisthogastric cuticle without metapodal plates.

.... Hypoaspisella egenus (Berlese, 1918) comb.n.

Nothing is known about the feeding patterns or any other aspects of $H$. pini's behavior. Its normal morphology (like that of other free-living $\mathrm{Hy}$ - 
poaspisella species) - e.g., dentate chelicerae, sclerotized and horn-like corniculi-suggests that it may be a predator of small invertebrates. We stress that further experimental work is needed to establish the true role of this mite in its respective ecosystems.

\section{ACKNOWLEDGEMENTS}

This research was supported by a grant from the Russian Science Foundation, project № 20-6447015. We cordially thank Dr. Alexander Khaustov (Tyumen State University, Russia) for his help in collecting samples, Vladimir Salavatulin (Tyumen State University) for his help in sorting samples and other technical assistance and Roman Latyntsev (Tyumen State University) for his help with logistics. We are deeply grateful to the Museum für Naturkunde Berlin, Zoologische Staatssammlung München, Germany (to Drs. Jason A. Dunlop and Anja Friederichs, in particular) for their hospitality of the senior author during his visit to the Museum.

\section{REFERENCES}

Athias-Henriot, C. 1971. La divergence néotaxique des Gamasides (Arachnides). Bulletin Scientifique de Bourgogne, 28: 93-106.

Athias-Henriot, C. 1975. Nouvelles notes sur les Amblyseiini. II. Le relevé organotaxique de la face dorsale adulte (Gamasides, protoadéniques, Phytoseiidae). Acarologia, 17: 20-29.

Berlese, A. 1918. Centuria quarta di Acari nuovi. Redia, 13: 115-192.

Bernhard, F. 1971. Gangsystematik der Parasitiformes. Teil 81. Die Gattung Hypoaspis G. Canestrini 1885. (Eine systematische Studie aus dem Jahre 1955). Acarologie. Schriftenreihe für Vergleichende Milbenkunde, 15: 2-10.

Costa, M. 1969. New dermanyssid mites (Acari: Mesostigmata) from nests of Spalax ehrenbergi Nehring. Acarologia, 11: 163-174.

Evans, G.O. 1963a. Observations on the chaetotaxy of the legs in the free-living Gamasina (Acari: Mesostigrnata). Bulletin of the British Museum (Natural History) Zoology, 10: 275-303. DOI: 10.5962/bhl. part.20528

Evans, G. O. 1963b. Some observations on the chaetotaxy of the pedipalps in the Mesostigmata (Acari). Annals and Magazine of Natural History, 13: 513-527. DOI: 10.1080/00222936308651393

Evans, G.O. and Till, W.M. 1966. Studies on the British Dermanyssidae (Acari: Mesostigmata). Part II. Classification. Bulletin of the British Museum (Natural History) Zoology, 14: 107-370.

Evans, G.O. and Till, W.M. 1979. Mesostigmatid mites of Britain and Ireland (Chelicerata: Acari: Para- sitiformes). Transactions of the Zoological Society of London, 35: 139-270.

Faraji, F., Abedi, L. and Ostovan, H. 2008. A new species of Hypoaspis Canestrini from Iran with a key to the Iranian species of Hypoaspis (Acari, Gamasina, Hypoaspididae). Zoosystematics and Evolution, 84: 205-209.

Farrier, M.H. and Hennessey, M.K. 1993. Soil-inhabiting and free-living Mesostigmata (Acari-Parasitiformes) from North America. An annotated checklist with bibliography and index. North Carolina Agricultural Research Service Technical Bulletin, 302: 1-408.

Hirschmann, W., Bernhard, F., Greim, E. and Götz, H. 1969. Zwanzig neue Hypoaspis-Arten. Acarologie. Schriftenreihe für Vergleichende Milbenkunde, 12: 133-141.

ICZN (International Commission on Zoological Nomenclature). 1999. International Code of Zoological Nomenclature. $4^{\text {th }}$ edition. The International Trust for Zoological Nomenclature, London. $306 \mathrm{pp}$.

Joharchi, O., Halliday, B., Khaustov, A. A. and Ermilov, S. G. 2018. Some soil-inhabiting mites from Zanzibar (Acari: Laelapidae). Zootaxa, 4514: 23-40.

Johnston, D.E. and Moraza, M.L. 1991. The idiosomal adenotaxy and poroidotaxy of Zerconidae (Mesostigmata: Zerconina). In: F. Dusbábek and V. Bukva (Eds.). Modern Acarology. Academia, Prague, vol. 2, pp. 349-356.

Karg, W. 1962. Zur Systematik und Postembryonalen Entwicklung der Gamasiden (Acarina, Parasitiformes) landwirtschaftlich genutzter Boden. Mitteilungen aus dem Zoologischen Museum in Berlin, 38: 23-119.

Karg, W. 1979. Die Gattung Hypoaspis Canestrini 1884 (Acarina, Parasitiformes). Zoologische Jahrbücher Abteilung für Systematik Ökologie und Geographie der Tiere, 106: 65-104.

Karg, W. 1982. Zur Kenntnis der Raubmilbeng Hypoaspis Canestrini, 1884 (Acarina, Parasitiformes). Mitteilungen aus dem Zoologischen Museum in Berlin, 58: 233-256.

Karg, W. 1993. Acari (Acarina), Milben. Parasitiformes (Anactinochaeta). Cohors Gamasina Leach, Raubmilben. Die Tierwelt Deutschlands, 59: 1-523.

Kavianpour, M., Karimpour, Y., Nemati, A. and Mirfakhraei, S. 2017. A faunistic study on laelapid mites in Urmia, Iran. Iranian Journal of Animal Biosystematics, 13(2): 159-170.

Kazemi, S. and Rajaei, A. 2013. An annotated checklist of Iranian Mesostigmata (Acari), excluding the family Phytoseiidae. Persian Journal of Acarology, 2(1): $63-158$. 


\section{O. Joharchi et al.}

Kazemi, S., Rajaei, A. and Beaulieu, F. 2014. Two new species of Gaeolaelaps (Acari: Mesostigmata: Laelapidae) from Iran, with a revised generic concept and notes on significant morphological characters in the genus. Zootaxa, 3861: 501-530.

Lapina, I.M. 1976. Free-living gamasoid mites of the family Laelaptidae Berlese, 1892 in the fauna of Latvian SSR. Latvijas Entomologs, 19: 20-64.

Lindquist, E.E. and Evans, G.O. 1965. Taxonomic concepts in the Ascidae with a modified setal nomenclature for the idiosoma of the Gamasina (Acarina: Mesostigmata). Memoirs of the Entomological Society of Canada, 47: 1-64.

McGraw, J.R., Farrier, M.H. 1969. Mites of the superfamily Parasitoidea (Acarina: Mesostigmata) associated with Dendroctonus and Ips (Coleoptera: Scolytidae). North Carolina Agricultural Experiment Station Technical Bulletin, 192: 1-162.

Moreira, G.F. 2014. Taxonomic Studies of Laelapid Mites (Acari: Mesostigmata: Laelapidae) and Their
Use in Combination with Entomopathogenic Nematodes (Rhabditida: Steinernematidae, Heterorhabditidae) to Control Frankliniella occidentalis (Thysanoptera: Thripidae). Ph.D. thesis. Universidade Estadual Paulista-Unesp Campus de Jaboticabal, Brazil. 522 pp.

Nemati, A., Riahi, E., Khalili-Moghadam, A. and Gwiazdowicz, D.J. 2018. A catalogue of the Iranian Mesostigmata (Acari): additions and updates of the previous catalogue. Persian Journal of Acarology, 7: 115-191. DOI: 10.22073/pja.v7i2.36985

Solomon, L. 1968. Une nouvelle espece du genre $H y$ poaspis (Acari: Dermanyssidae). Travaux $d u$ Muséum d'Histoire Naturelle Grigore Antipa, 8(2): 663-669. [In French]

Walter, D.E. and Krantz, G.W. 2009. Collecting, rearing and preparing specimens. In: G. W. Krantz and D.E. Walter (Eds.). A Manual of Acarology. $3^{\text {rd }}$ edition. Texas Tech University Press, Lubbock, Texas, pp. 83-95. 